\title{
A Comparative Study between Dexmedetomidine Alone versus Combined Low Dose of Dexmedetomidine and Lidocaine for the Hemodynamic Response to Endotracheal Extubation in Patient Undergoing Abdominal Surgery-A Prospective Randomized Controlled Study
}

\author{
El-Sayed Mohamed Abdelzaam ${ }^{*}$, Ayman Mohamady Eldemrdash ${ }^{2}$ \\ ${ }^{1}$ Department of Anesthesiology, Faculty of Medicine, Benha University, Benha, Egypt \\ ${ }^{2}$ Department of Anesthesiology, Faculty of Medicine, Aswan University, Aswan, Egypt \\ Email: *sa yedzim12@yahoo.com, aymaneldemrdash@ya hoo.com
}

How to cite this paper: Abdelzaam, E.-S.M. and Eldemrdash, A.M. (2019) A Comparative Study between Dexmedetomidine Alone versus Combined Low Dose of Dexmedetomidine and Lidocaine for the Hemodynamic Response to Endotracheal Extubation in Patient Undergoing Abdominal Surgery-A Prospective Randomized Controlled Study. Open Journal of Anesthesiology, 9, 111-126.

https://doi.org/10.4236/ojanes.2019.96011

Received: May 13, 2019

Accepted: June 11, 2019

Published: June 14, 2019

Copyright $\odot 2019$ by author(s) and Scientific Research Publishing Inc. This work is licensed under the Creative Commons Attribution International License (CC BY 4.0).

http://creativecommons.org/licenses/by/4.0/

\begin{abstract}
Background: Tracheal extubation is related to many side effects of hemodynamic, especially for patients with comorbid states. The study compared the validity of dexmedetomidine $1 \mu \mathrm{g} / \mathrm{kg}$ and low combination dose of dexmedetomidine $0.5 \mu \mathrm{g} / \mathrm{kg}$ plus Lidocaine $1 \mathrm{mg} / \mathrm{kg}$ in softening hemodynamic stress response and estimated quality of extubation in study groups. Materials and Methods: The patients in our study, one hundred and fifty of both gender, ASA class I \&II patients, aged 20 - 50 years old subject to elective abdominal operations under general anesthesia were allocated into three equal groups. Anesthetic technique was standardized. Before extubation by 10 minutes, the patients in Group N, D, and DL have given $0.9 \%$ normal Saline intravenous bolus infusion, dexmedetomidine $1 \mu \mathrm{g} / \mathrm{kg}$ and Dexmedetomidine $0.5 \mu \mathrm{g} / \mathrm{kg}$, respectively within a 10 -minute period. Before complete extubation by 90 seconds, in the three groups by syringe ten cc volumes and at time of extubation, Group N and D patients received $0.9 \%$ normal Saline intravenous bolus infusion, but in Group DL received Lidocaine $1 \mathrm{mg} / \mathrm{kg}$ then extubation completed. Heart rate (HR), Diastolic BP (DBP), Systolic BP (SBP), and Mean Arterial Pressure (MAP) were noted at baseline, at the reverse, extubation, 2, $4,6,8,10$ min and at the regular times after that for two hours. Extubation
\end{abstract}


quality was assessed by extubation quality scale. Aldrete's recovery score and Ramsay sedation score were also recorded and also any complications were noted and recorded. Results: All the hemodynamic parameters significantly elevated extubation and numerous periods of observation in the normal saline group than dexmedetomidine and dexmedetomidine plus Lidocaine group (p-value $=0.001)$. Response of tachycardia was seen in $41(82 \%)$ in patients of $\mathrm{N}$ group, compared to $18(36 \%)$ and 20 (40\%) in D \& DL group respectively $(\mathrm{p}=0.001)$. Hypertensive response statistically significant noticed in $40(80 \%)$ patients of $\mathrm{N}$ group, $9(18 \%)$ of D group and $12(24 \%)$ of DL group $(\mathrm{p}=0.001)$. Tachycardia duration and the response of hypertension were significantly prolonged in the control group. As regards extubation quality, the three groups differed in D Groups $(1.93 \pm 0.57)$ and DL $(1.51 \pm$ $0.57)$ had decreased scores compared to group $\mathrm{N}(2.67 \pm 0.48)$ modulating smoother extubation $(\mathrm{p}<0.001)$. As regard to Ramsay sedation score for 25 min following incoming at PACU was Groups D (2.17 \pm 0.43$)$, DL (2.07 \pm $0.35)$ and had raised sedation scores when compared to group $\mathrm{N}(1.93 \pm 0.28)$ $(\mathrm{p}<0.003)$. Conclusion: Low combined dose of (Dexmedetomidine 0.5 $\mu \mathrm{g} / \mathrm{kg}$ plus Lidocaine $1 \mathrm{mg} / \mathrm{kg}$ ) IV was useful as much as Dexmedetomidine 1 $\mu \mathrm{g} / \mathrm{kg}$ IV in softening hemodynamic stress responses during emergence.

\section{Keywords}

Dexmedetomidine, Lidocaine, Emergence, Extubation Quality

\section{Introduction}

Sympathetic reflex is almost always associated with hemodynamic changes during endotracheal intubation and extubation as well. Due to stimulation of epipharyngeal and laryngopharyngealso, tracheal extubation is as challenging as intubation in anesthesia practice. These hemodynamic changes result in arrhythmias and hypertension. The elevation in heart rate and blood pressure is usually unpredictable. It is more dangerous to the patient with hypertension, myocardial insufficiency or cerebrovascular diseases [1].

Tracheal extubation may cause cough or difficulties in breathing and may lead to an elevation in blood pressure. Respiratory complications incidences after extubation have been three times more common than during intubation that prevalence (4.6\% versus $12.6 \%$ ) [2]-[9].

Smooth tracheal extubation results in the absence of straining, movement, coughing, breath-holding or laryngospasm. By different techniques and available antihypertensive drugs attenuate airway and circulatory reflexes during extubation, but none have been entirely successful. Many attempts of methods have been made to decrease the pressor response by the use of many drugs such as narcotic analgesics, deep anesthesia induced by inhalational anesthetics, local anesthetics, adrenoceptor blockers, and vasodilator agents [2]. 
Additional studies have been carried out with the use of diltiazem, lignocaine, esmolol, labetalol, nicardipine, and opioids as the sole agent or in comparison with each other. Many types of research is still try to detect a perfect and typical drug with a right protective margin, which decreases nearly of the hemodynamic changes in response to airway stimulation at tracheal extubation with good quality and without delaying recovery and without causing complications (such as sedation, respiratory depression, hypotension, etc.).

To decrease airway and pressor response during tracheal extubation, dexmedetomidine, a highly selective alpha-two adrenoceptor agonist has studied as a single dose, at the time of extubation and as an anesthetic adjuvant. It's a sympatholytic effect through decreases in the concentration of norepinephrine. [3] [5]. This, in turn, decreases the heart rate (HR) and blood pressure. Dexmedetomidine, therefore, is theoretically appropriate for reducing airway and circulatory reflexes during emergence from anesthesia [6].

Lignocaine, a local amide anesthetic, injected intravenously or topically applied to larynx and trachea, is variably effective at blunting the hemodynamic response to tracheal stimulation. Lignocaine also has been used to decrease these reflexes during extubation [10] [11]. It attenuates the hemodynamic response to tracheal extubation by its direct myocardial depressant effect, central stimulant effect, peripheral vasodilatory effect, and finally, it suppresses the cough reflex, an effect on synaptic transmission [12]. It also prevents the rise in intracranial pressure associated with tracheal suctioning and may to avoid the increase in intraocular pressure seen with tracheal extubation. It also decreases intracellular calcium concentration in airway smooth muscle, decreases myofilament calcium sensitivity and that cause prevents reflex bronchoconstriction and suppresses the cough reflex [10] [11].

As the pharmacological mechanism controlling the hemodynamic changes during extubation is different between dexmedetomidine and lidocaine, the concomitant use of these drugs may enhance the prophylactic effect of each drug alone for this purpose [12]. Therefore, our study was designed to compare the efficacy of low dose of dexmedetomidine plus lidocaine with stander dose of dexmedetomidine $(1 \mu \mathrm{g} / \mathrm{kg})$ alone in suppressing the hemodynamic changes and catecholamine responses during extubation in abdominal surgery.

The aim of this study is reasonable to have rapid emergence and extubation without any adverse hemodynamic and airway changes in abdominal surgery with less sedation and high extubation quality [2].

Hence, We proceeded a prospective randomized controlled clinical trial with the primary target for assessment of the efficacy of dexmedetomidine $(1 \mu \mathrm{g} / \mathrm{kg})$ as standardized dose and low combined dose of (dexmedetomidine $0.5 \mu \mathrm{g} / \mathrm{kg}$ plus Lidocaine $1 \mathrm{mg} / \mathrm{kg}$ ) respectively IV for attenuating stress response and compared extubation quality score in all study groups under equally standard anesthetic condition by applying the entropy and nerve stimulator. We also estimated quality recovery score, sedation score and other side effects amongst the three groups in the PACU over 2 hours. 


\section{Patient and Methods}

One hundred and fifty patients of both sex of American Society of Anesthesiologists classes I or II, aged 20 - 50 years old, shceduled for elective abdominal surgeries taking about 90 - 240 minutes, under general anesthesia needing intubation with an endotracheal tube, registered for the study. Written informed consent was taken from patients. Data were accumulated through six months (Nov 2018-April 2019) at Benha and Aswan University. The study was approved by the institutional review board (Hospital Ethics Committee for Human Research).

\subsection{Exclusion Criteria}

Patients were with renal impairment (serum creatinine more than $1.5 \mathrm{mg} / \mathrm{dl}$ ), cardiorespiratory abnormalities (bronchial asthma, COPD, and restrictive lung disease, Hypertension, New York Heart Association heart failure grades III and IV), and liver dysfunction. Significant obesity (body mass index more than 35), patients with a difficult air way, and emergency procedures were excluded from the study.

\subsection{Sample Size Calculation}

The sample size was estimated based on previous research that studied the influence of dexmedetomidine on extubation response directed by D Jain and coworkers, [13] who observed an elevation in Systolic Blood Pressure of $32.3 \pm 11$ $\mathrm{mmHg}$ in the control group during extubation. We created that a $20 \%$ decrease in extubation stress response in the study drug group should be clinically significant. The group size was detected by using the sample size detection "for two groups means method" with $1 \%$ significance and $90 \%$ power, based on which, we needed to study 43 patients in each group. So we added $10 \%$ compensation for "loss to follow up" and for the inclusion of a group three into our study. We obtain 50 patients in each group.

\subsection{Randomization}

Randomization was done by a computer-generated random number (created using Microsoft Excel 2003 software, Redmond, WA). The patients were randomized into three groups, with 50 patients in each group. Groups $\mathrm{N}, \mathrm{D}$, and DL were given intravenous bolus infusion (over 10 minutes) of $0.9 \%$ Normal Saline, $1 \mu \mathrm{g} / \mathrm{kg}$ Dexmedetomidine and low combination dose of dexmedetomidine 0.5 $\mu \mathrm{g} / \mathrm{kg}$, plus Lidocaine $1 \mathrm{mg} / \mathrm{kg}$ respectively, 10 minutes before extubation.

\subsection{Intraoperative Period}

As the standard monitors (Electrocardiography (ECG), pulse oximetry, non-invasive blood pressure, and temperature monitoring), nerve stimulators TOF-watch were used during the intraoperative period. Before induction heart rate (HR), diastolic blood pressure (DBP), systolic blood pressure (SBP), mean arterial blood pressure (MAP) and oxygen saturation was noted.

After pre-oxygenation for 3 minutes, the induction was with intravenous fen- 
tanyl $2 \mu \mathrm{g} / \mathrm{kg}$ propofol $2 \mathrm{mg} / \mathrm{kg}$ and muscle relaxation was achieved with rocuronium $0.8 \mathrm{mg} / \mathrm{kg}$ and Muscle relaxant were achieved with rocuronium 0.8 $\mathrm{mg} / \mathrm{kg}$. After completing TOF count of zero, as smooth and gentle laryngoscopy and endotracheal intubation were performed with suitable size endotracheal tube. Anesthesia was continued with isoflurane $(0.8 \%-1.5 \%)$ in oxygen and NO (50:50). Muscle relaxation was continued and maintained with vecuronium 0.8 $\mathrm{mg} / \mathrm{kg}$. Intra-operative analgesia was continued and maintained by using fentanyl $0.5-1 \mu \mathrm{g} / \mathrm{kg} / \mathrm{hr}$ IV infusion.

Vital parameters determined within $20 \%$ of baseline values. Fentanyl infusion was stopped 20 - 30 minutes before the anticipated time of extubation. Isoflurane discontinued at the time of skin closure and HR, SBP, DBP, and MAP detected as "Baseline" value.

Groups N, D, and DL received intravenous bolus infusion of $0.9 \%$ Normal Saline, $1 \mu \mathrm{g} / \mathrm{kg}$ of Dexmedetomidine and dexmedetomidine $0.5 \mu \mathrm{g} / \mathrm{kg}$ respectively, infused over 10 minutes begin from 10 minutes before extubation. After the onset of spontaneous breathing, intravenous glycopyrrolate $0.01 \mathrm{mg} / \mathrm{kg}$ and neostigmine were administered to reverse the muscle relaxants effects. When the extubation criteria were fulfilled, patients were extubated. Just before extubation, all groups and by syringe ten cc volume and at time of extubation patients in Group N and D received $0.9 \%$ normal Saline intravenous bolus infusion, but in Group DL received Lidocaine $1 \mathrm{mg} / \mathrm{kg}$ then extubation was completed after 90 seconds so all were the blind giver and observer.

HR, DBP, SBP, and MAP noted and recorded at reversal, then at extubation, and also every $2 \mathrm{~min}$ for $10 \mathrm{mins}$, then every $5 \mathrm{mins}$ for first $30 \mathrm{mints}$, and last every $30 \mathrm{~min}$ for next one hour after extubation. Extubation quality estimated on 5-point extubation quality scale [14] [15]:

$1=$ there is no coughing,

2 = smooth extubation, there is minimal coughing ( 1 or 2 times),

$3=$ there is moderate coughing ( 3 or 4 times),

$4=$ there is severe coughing $(5-10$ times $)$ and present of straining,

$5=$ poor extubation (laryngospasm and coughing $>10$ times).

Ramsay sedation score [16] [17] and Aldrete's Recovery score were noted and recorded every $15 \mathrm{~min}$ after extubation for 2 hours.

Ramsay scale:

1) Anxious or agitated and restless or both.

2) Cooperative, oriented and tranquil.

3) Drowsy but responds to commands.

4) Asleep, brisk response to a light glabellar tap or loud auditory stimulus.

5) Asleep, sluggish response to a light glabellar tap or loud Auditory.

6) Asleep and un arousable.

Any reversed events as elevated blood pressure, increase heart rate, drop in blood pressure, decrease in heart rate $(<30 \%$ of baseline value), desaturation, bronchospasm was noted and managed accordingly. 
Statistical analysis was done using SPSS version 15. Data were presented as Mean (SD) or number (\%). The qualitative data were compared by applying Chi-Square or Fisher's exact test. The quantitative data were analyzed by using one-way ANOVA followed by post hoc comparison by Bonferroni method. To see the change over time, repeated measure analysis was applied followed by post hoc comparison by least square deviation method separately for each group. Statistical significance was accepted when $\mathrm{p}$-value at $\mathrm{P}<0.05$.

\section{Results}

The total 150 patients randomly were sectioned into three groups 50 for each, receiving 9\% normal saline (group N), dexmedetomidine (group D) and Dexmedetomidine and Lidocaine (group DL) 10 minutes before extubation. Then in all groups in syringe ten $\mathrm{cc}$ volumes and at time of extubation, patients in Group $\mathrm{N}$ and $\mathrm{D}$ received intravenous bolus infusion of $0.9 \%$ normal Saline bolus infusion, but in Group DL received Lidocaine $1 \mathrm{mg} / \mathrm{kg}$ then extubation was completed after 90 seconds. In group D, we were excluded one patient from analysis because of insufficient accumulation of hemodynamic data. The demographical data were well compared in the three groups concerning age, sex, weight, ASA grade, and duration of surgery (Table 1, Figure 1).

\subsection{Hemodynamic Parameters}

Baseline value: Haemodynamic variables such as Heart Rate (HR), Systolic Blood Pressure (SBP), Diastolic Blood Pressure (DBP), and Mean Blood Pressure (MAP) measured before using of study drug, after discontinuation of is of lurane. The three groups were well compared concerning baseline HR, SBP, DBP, and MAP.

\subsection{Heart Rate}

Extreme heart rate (HR) recorded in Group $\mathrm{N}$ was $109 \pm 11$ beat per min., which was significantly higher when compared to the other two groups ( $p=0.001)$. The average elevation in HR above baseline noticed in group $\mathrm{N}(33 \pm 10 \mathrm{bpm})$ was considerably more $(\mathrm{p}=0.001)$. Tachycardia response was seen in $82 \%$ of patients in group $\mathrm{N}$, compared to $36 \%$ and $40 \%$ in group D \& DL respectively

Table 1. Demographics data.

\begin{tabular}{ccccc}
\hline Demography & $\begin{array}{c}\text { Group N } \\
(\mathrm{n}=50)\end{array}$ & $\begin{array}{c}\text { Group D } \\
(\mathrm{n}=49)\end{array}$ & $\begin{array}{c}\text { Group DL } \\
(\mathrm{n}=50)\end{array}$ & p-Value \\
\hline Age (yrs) & $34.46 \pm 9.07$ & $36.80 \pm 8.06$ & $35.66 \pm 10.73$ & 0.977 \\
Sex $\quad$ Male: Female (\%) & $14: 36(28: 72)$ & $21: 29(42: 58)$ & $24: 26(48: 52)$ & 0.588 \\
$\quad$ Weight (kg) & $64.36 \pm 12.43$ & $62.78 \pm 12.24$ & $63.98 \pm 11.89$ & 0.975 \\
ASA-grade 1:2 (\%) & $39: 11(78: 22)$ & $41: 8(82: 16)$ & $40: 10(80: 20)$ & $>0.05$ \\
Duration of surgery (hrs) & $2.33 \pm 0.73$ & $2.25 \pm 0.83$ & $2.27 \pm 0.71$ & 0.414 \\
\hline
\end{tabular}

Data are presented as mean (SD) or number (\%). N: Normal saline, D: Dexmedetomidine, DL: Dexmedetomidine plus lidocaine. 

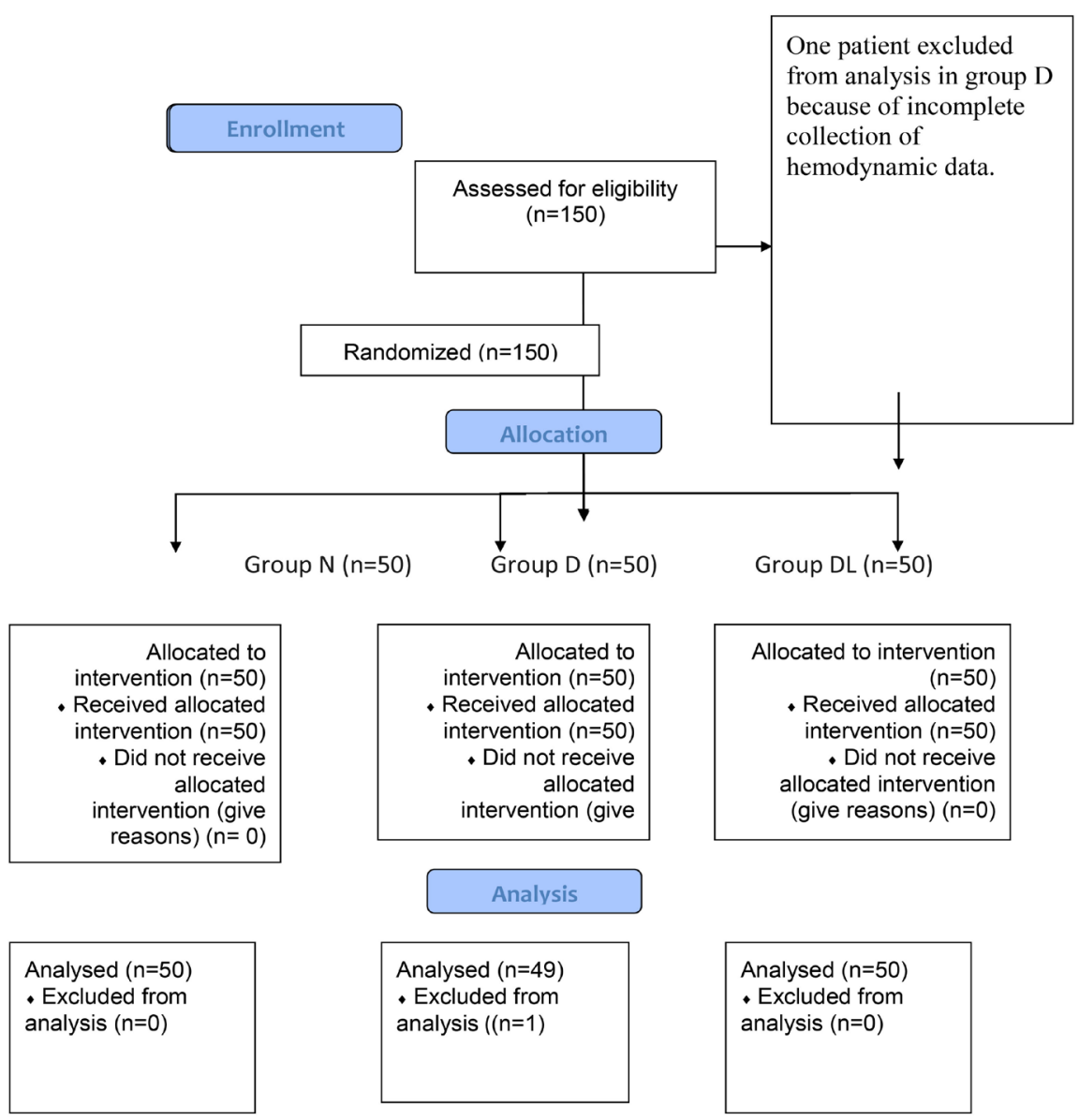

Figure 1. Consort flow diagram.

$(\mathrm{p}=0.001)$. Duration of tachycardia was significantly longer $(19 \pm 23 \mathrm{~min})$ in group $\mathrm{N}$ compared to group $\mathrm{D}(6 \pm 5 \mathrm{~min})$ and group $\mathrm{DL}(8 \pm 2 \mathrm{~min})(\mathrm{p}=0.001)$ (Table 2, Figure 2).

Maximum values of DBP, SBP, and MAP attained in groups N, D and DL were statistically significant $(\mathrm{p}=0.001)$. The magnitude of increase in SBP, DBP, and MAP above baseline was highest in Group N which was statistically significant $(\mathrm{p}=0.001)$.

\subsection{Systolic Blood Pressure}

Maximum Systolic Blood Pressure observed in group N, D and DL were $158 \pm$ $14,132 \pm 17$ and $135 \pm 8 \mathrm{mmHg}$ which was statistically significant $(\mathrm{p}=0.001)$. Statistically significant Hypertensive response noticed in $40(80 \%)$ patients of group N, $9(18 \%)$ of group D and $12(24 \%)$ of group DL ( $\mathrm{p}=0.001)$. The average duration of hypertension also remained significantly highest in group $\mathrm{N}$ ( $\mathrm{p}<$ 0.05) (Table 3, Figure 3).

\subsection{Diastolic Blood Pressure}

Maximum rise in Diastolic Blood Pressure in groups N, D, and DL was $89 \pm 12$, $79 \pm 7$ and $82 \pm 7 \mathrm{mmHg}$ respectively, which was statistically significant ( $\mathrm{p}=$ 
Table 2. Heart rate.

\begin{tabular}{ccccc}
\hline Heart Rate & Group N & Group D & Group DL & P value \\
\hline Baseline & $73 \pm 11$ & $71 \pm 8$ & $73 \pm 7$ & 0.54 \\
Max. value (Bpm) & $109 \pm 11$ & $92 \pm 12$ & $84 \pm 8$ & $0.001^{*}$ \\
$\begin{array}{c}\text { Maximum of increase above } \\
\text { baseline (\%) }\end{array}$ & $33 \pm 10$ & $18 \pm 9$ & $10 \pm 11$ & $0.001^{*}$ \\
$\begin{array}{c}\text { Number of patients } \\
\text { owing Tachycardia \&\% }\end{array}$ & $41(82 \%)$ & $18(36 \%)$ & $20(40 \%)$ & $0.001^{*}$ \\
$\begin{array}{c}\text { Average duration } \\
\text { of Tachycardia (min) }\end{array}$ & $19 \pm 23$ & $6 \pm 5$ & $8 \pm 2$ & $0.001^{*}$ \\
\hline
\end{tabular}

Values are expressed when Mean \pm SD or Number $(\%)^{*} \mathrm{P}<0.05$, statistically significant. N: Normal saline, D: Dexmedetomidine, DL: Dexmedetomidine plus lidocaine. Bpm: Beats per minute.

Table 3. Systolic blood pressure.

\begin{tabular}{|c|c|c|c|c|}
\hline Systolic Blood Pressure & Group N & Group D & Group DL & $\mathrm{P}$ value \\
\hline Baseline & $113 \pm 11$ & $112 \pm 17$ & $113 \pm 14$ & 0.88 \\
\hline Max. value (mmHg) & $158 \pm 14$ & $132 \pm 17$ & $135 \pm 8$ & $0.001^{*}$ \\
\hline $\begin{array}{l}\text { Maximum of increase } \\
\text { above baseline (\%) }\end{array}$ & $\begin{array}{c}47 \pm 13 \\
(43 \pm 13)\end{array}$ & $\begin{array}{c}24 \pm 14 \\
(23 \pm 13)\end{array}$ & $\begin{array}{c}26 \pm 13 \\
(24 \pm 14)\end{array}$ & $0.001^{\star}$ \\
\hline $\begin{array}{c}\text { Number of patients owing } \\
\text { Hypertension (\%) }\end{array}$ & $40(80 \%)$ & $9(18 \%)$ & $12(24 \%)$ & $0.001^{*}$ \\
\hline $\begin{array}{c}\text { Average Duration } \\
\text { of Hypertension ( } \mathrm{min} \text { ) }\end{array}$ & $21 \pm 28$ & $18 \pm 38$ & $19 \pm 4$ & $0.032^{*}$ \\
\hline
\end{tabular}

Values are expressed when Mean $\pm \mathrm{SD}$ or Number $(\%)^{\star} \mathrm{P}<0.05$, statistically significant. N: Normal saline, D: Dexmedetomidine, DL: Dexmedetomidine plus lidocaine.

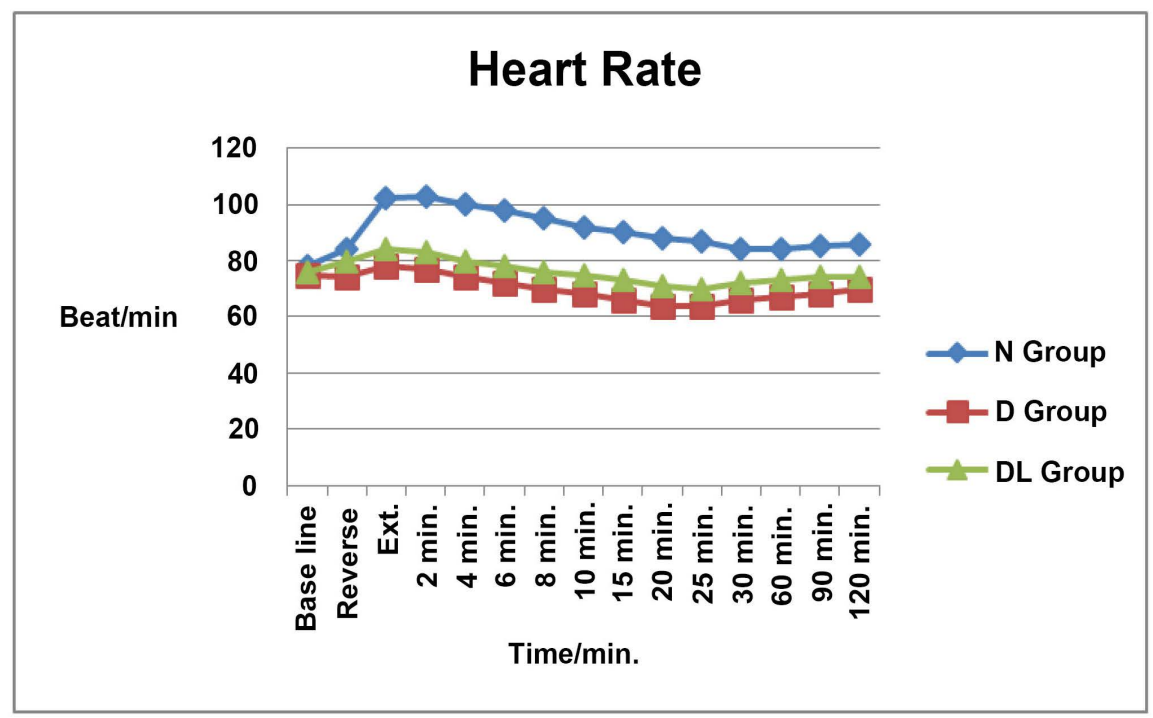

Figure 2. Heart rate.

0.001). The magnitude of increase in DBP above the baseline was $20 \pm 10 \mathrm{mmHg}$ (30\%) in group $\mathrm{N}, 12 \pm 8 \mathrm{mmHg}(18 \%)$ in group D and $12 \pm 8 \mathrm{mmHg}(18 \%)$ in group DL, which was statistically significant $(\mathrm{p}=0.001)$ (Table 4 , Figure 4$)$. 


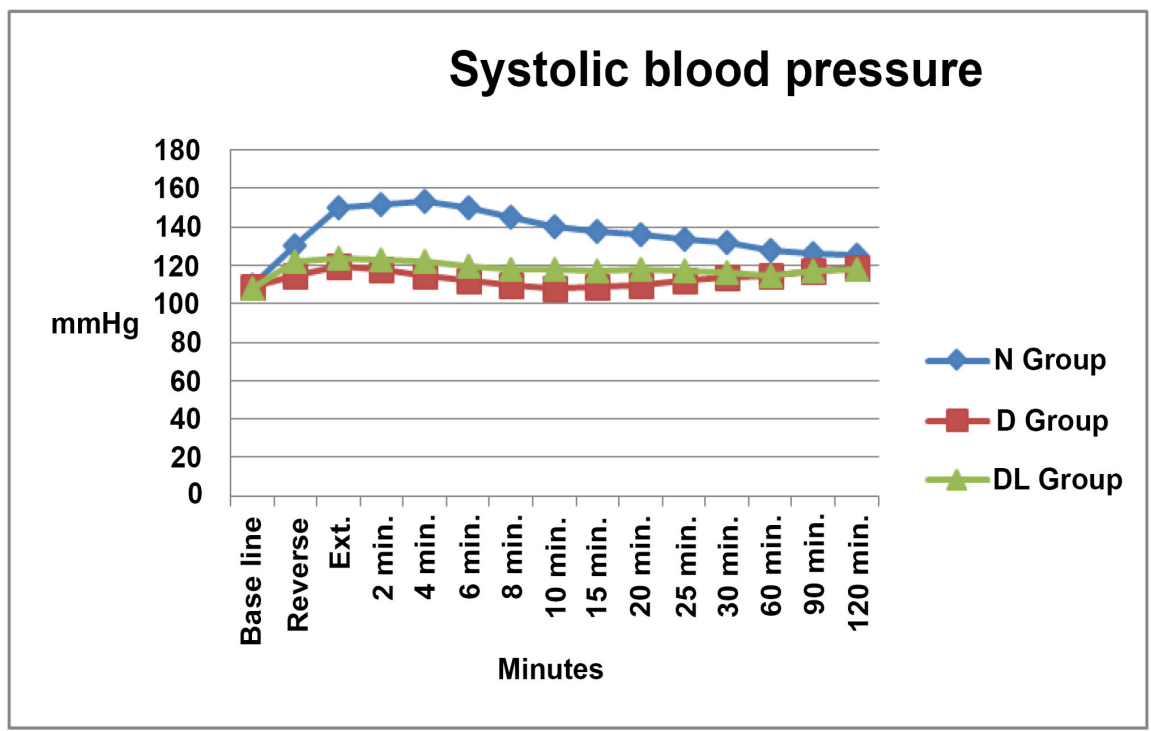

Figure 3. Systolic blood pressure.

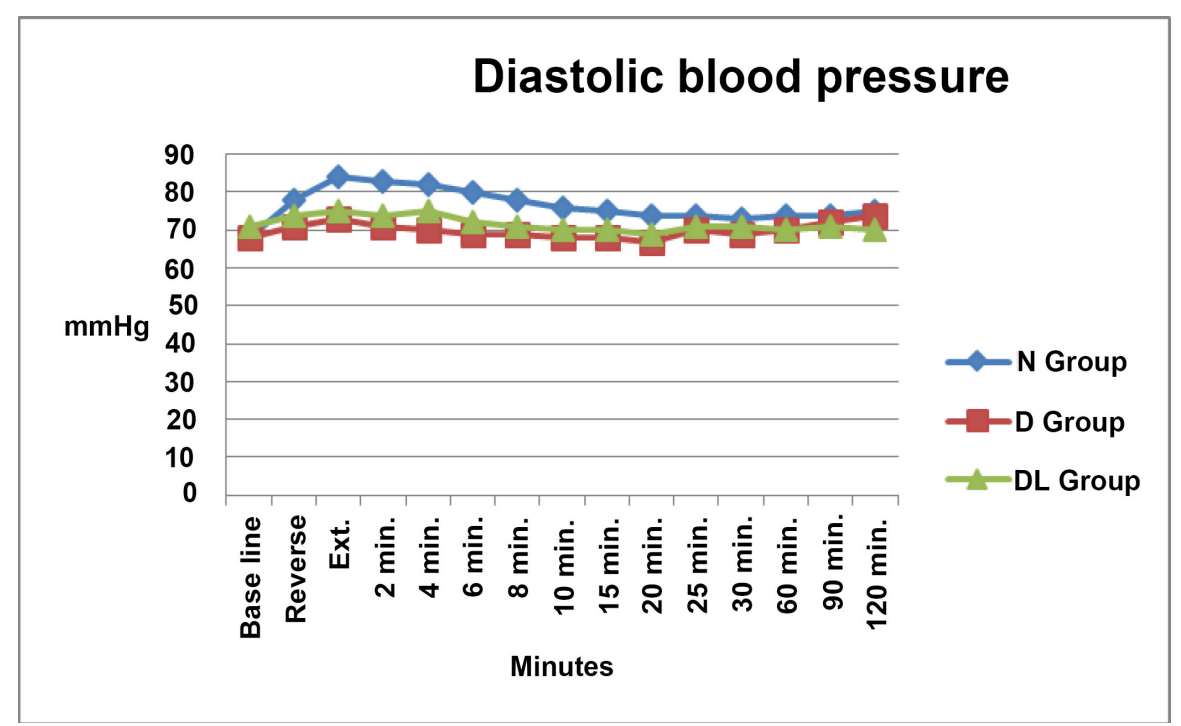

Figure 4. Diastolic blood pressure.

Table 4. Diastolic blood pressure.

\begin{tabular}{ccccc}
\hline Diastolic Blood Pressure & Group N & Group D & Group DL & P value \\
\hline Baseline & $68 \pm 7$ & $70 \pm 6$ & $69 \pm 9$ & 0.32 \\
Max. value & $89 \pm 12$ & $79 \pm 7$ & $82 \pm 7$ & $0.001^{*}$ \\
$\begin{array}{c}\text { Maximum of increase above } \\
\text { baseline (\%) }\end{array}$ & $20 \pm 10$ & $12 \pm 8$ & $12 \pm 8$ & $0.001^{*}$ \\
$\begin{array}{c}(30 \pm 22) \\
\text { percentage of patients owing } \\
\text { value } \geq \mathbf{3 0 \%} \text { of baseline (\%) }\end{array}$ & $16(32 \%)$ & $8(16 \%)$ & $9(18 \%)$ & $0.002^{*}$ \\
$\begin{array}{c}\text { Average Duration } \\
\text { of Hypertension (min) }\end{array}$ & $32 \pm 49$ & $13 \pm 47$ & $14 \pm 49$ & $0.002^{*}$ \\
\hline
\end{tabular}

Values are expressed when Mean $\pm \mathrm{SD}$ or Number $(\%)^{\star} \mathrm{P}<0.05$, statistically significant. N: Normal saline, D: Dexmedetomidine, DL: Dexmedetomidine plus lidocaine. 


\subsection{Mean Arterial Blood Pressure}

The extreme value of Mean Arterial Pressure observed in groups N, D, and DL were $111 \pm 12,98 \pm 8$ and $99 \pm 70 \mathrm{mmHg}$ respectively (p-value). The maximum of elevation above baseline in groups N, D, and DL was $28 \pm 11$ (33\%), $12 \pm 8$ (14\%), and $13 \pm 7$ (16\%) $\mathrm{mmHg}$ respectively which was statistically significant. $(\mathrm{p}=0.001)($ Table 5, Figure 5).

\subsection{Recovery Profile}

The minimal the extubation quality scale, the smoother was the extubation. Overall extubation quality the groups differed $(\mathrm{p}<0.001)$. Groups $\mathrm{D}(1.93 \pm 0.57)$ and DL $(1.51 \pm 0.57)$ decreased scores compared to group N (2.67 \pm 0.48$)$ implying softer extubation. Among group D and DL, group DL had best extubation quality (Figure 6).

There was a significant difference among the groups as regards to Ramsay sedation score $(\mathrm{p}<0.003)$ for $25 \mathrm{~min}$ after arrival at Post Anesthesia Care Unite. Groups D $(2.17 \pm 0.43) \mathrm{DL}(2.07 \pm 0.35)$ and had higher sedation scores compared to group $\mathrm{N}(1.93 \pm 0.28)$. During the latter part of the observation, there were no statistically and clinically significant changes among study groups (Figure 7).

\section{Discussion}

Laryngoscopy, endotracheal intubation, and extubation are considered to be the most critical events during general anesthesia. They trigger a transient but marked sympathetic response. The resulting hemodynamic pressure response has been a constant problem for anesthesiologists. Tracheal extubation is associated with similar problems as occurring during intubation. During extubation, increased heart rate and blood pressure may result in complications such as cardiac failure, pulmonary edema, and cerebral vascular hemorrhage. [18]

The proposed mechanism behind these hemodynamic changes is increased sympathetic activity and release of catecholamines.

Alpha-2 adrenergic drugs, such as dexmedetomidine or clonidine attenuate these potentially adverse events during induction of anesthesia [19] [20].

Table 5. Mean arterial blood pressure.

\begin{tabular}{ccccc}
\hline Mean Arterial Blood Pressure & Group N & Group D & Group DL & P value \\
\hline Baseline & $83 \pm 8$ & $85 \pm 9$ & $84 \pm 7$ & 0.399 \\
Max. value (mmHg) & $111 \pm 12$ & $98 \pm 8$ & $99 \pm 70$ & $0.001^{*}$ \\
$\begin{array}{c}\text { Maximum of increase } \\
\text { above baseline (\%) }\end{array}$ & $28 \pm 11$ & $12 \pm 8$ & $13 \pm 7$ & $0.001^{*}$ \\
$\begin{array}{c}\text { Percentage of patients owing } \\
\text { value } \geq 30 \% \text { of baseline (\%) } \\
\begin{array}{c}\text { Average Duration } \\
\text { of Hypertension (min) }\end{array}\end{array}$ & $22(44 \%)$ & $4(8 \%)$ & $5(10 \%)$ & $0.001^{*}$ \\
\hline
\end{tabular}

Values are expressed when Mean \pm SD or Number $(\%)^{\star} \mathrm{P}<0.05$, statistically significant. N: Normal saline, D: Dexmedetomidine, DL: Dexmedetomidine plus lidocaine. 


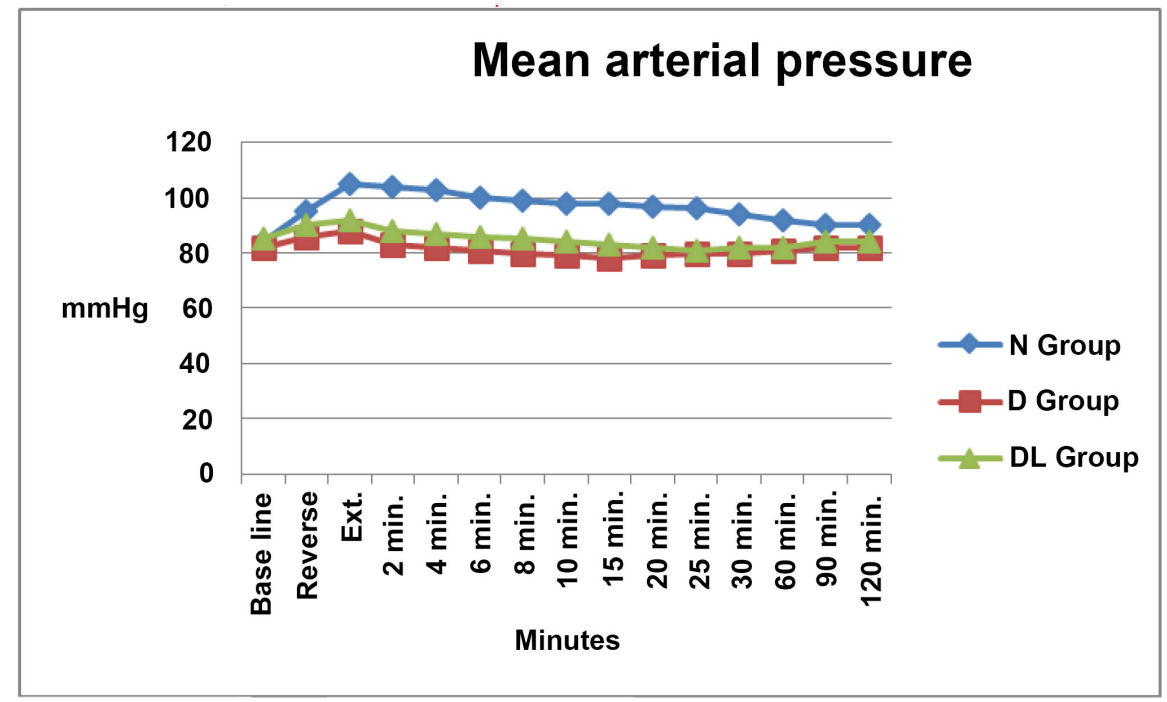

Figure 5. Mean arterial pressure.

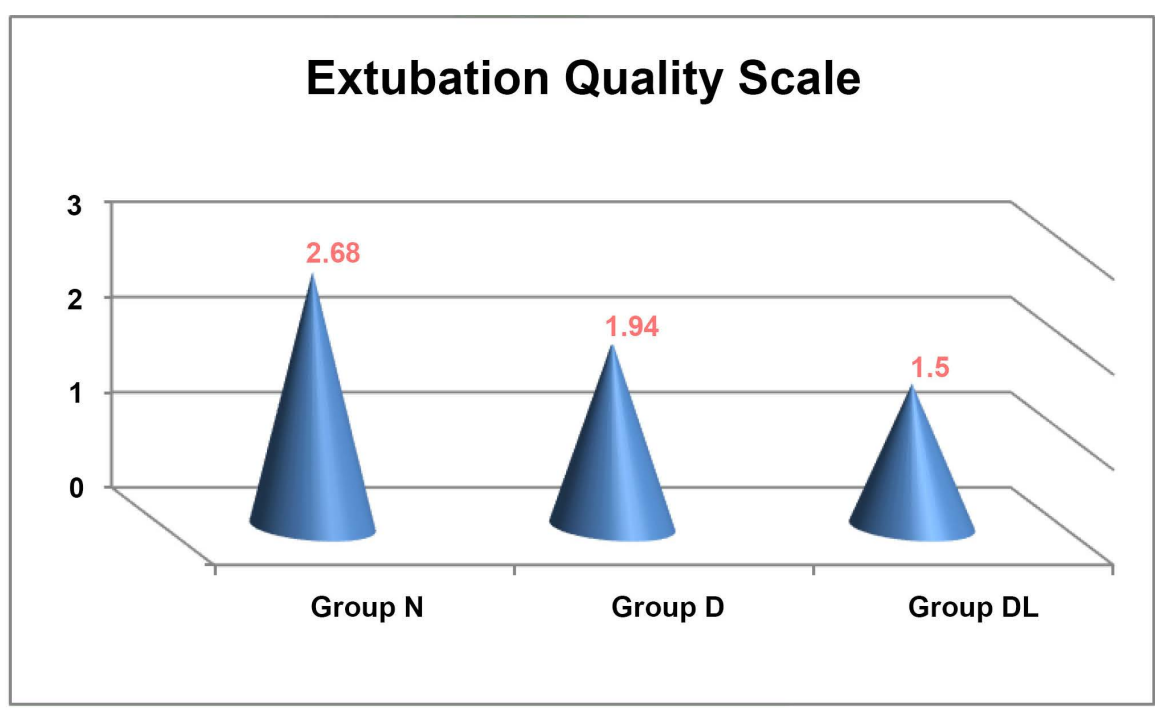

Figure 6. Average extubation quality scale.

The target of this study, we compared stander dexmedetomidine single dose 1 $\mu \mathrm{g} / \mathrm{kg}$, a newer $\alpha-2$ agonist with a low single combined dose of (dexmedetomidine $0.5 \mu \mathrm{g} / \mathrm{kg}$ plus Lidocaine $1 \mathrm{mg} / \mathrm{kg}$ ) for attenuating hemodynamic response to tracheal extubation.

Dexmedetomidine is the alpha-2 agonist, a sedative and analgesic, reduces blood pressure and heart rate dose-dependently. Coworkers and Guler G [21] evaluated single-dose dexmedetomidine $1 \mu \mathrm{g} / \mathrm{kg}$ in attenuating circulatory reflexes and airway reflexes during extubation. They concluded that a single-dose bolus injection of dexmedetomidine when given before extubation by 5 minutes leading to decrease of airway-circulatory reflexes without extending the recovery. Also, Recep Aksu et al. [22] have found that a single-dose bolus injection of dexmedetomidine $0.5 \mu \mathrm{g} / \mathrm{kg} \mathrm{IV}$, when given before tracheal extubation, 


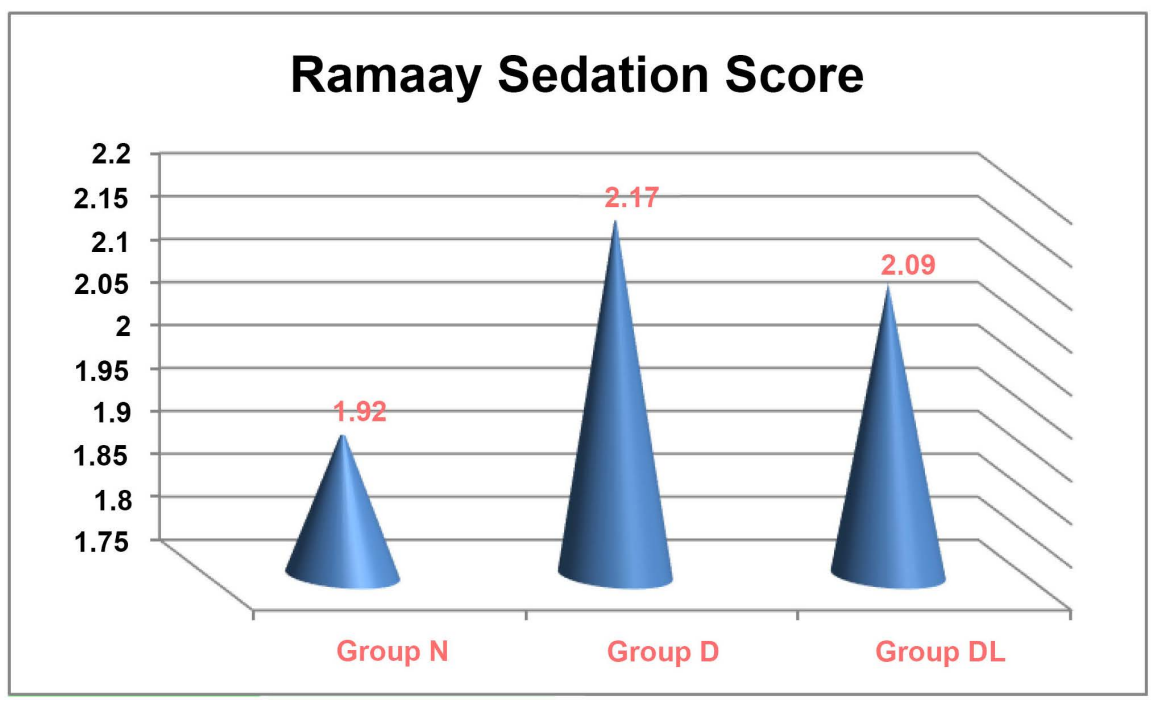

Figure 7. Ramsay sedation score.

attenuates airway-circulatory reflexes better compared to fentanyl $1 \mu \mathrm{g} / \mathrm{kg}$ IV without prolonging recovery. Dexmedetomidine-induced the reduction of HR and blood pressure during extubation is mainly dose-dependent, that is, higher doses are more effective than the lower doses [23]. Many studies showed that dexmedetomidine in dosage $0.5-1 \mu \mathrm{g} / \mathrm{kg} \mathrm{IV}$ is administered as bolus infusion $10-15 \mathrm{mi}-$ nutes before extubation stabilizes hemodynamics and facilitates smooth extubation compared to the control group [15] [24] [25] [26] [27].

Bindu et al. studied the effective dose of $0.75 \mu \mathrm{g} / \mathrm{kg}$ of dexmedetomidine in a throughout $15 \mathrm{~min}$ before the end of the surgery, and they observed that dexmedetomidine decreased the hemodynamic responses and produced smooth extubation with an increased incidence of hypotension, bradycardia, and a higher level of postoperative sedation score. [26]. In our study, dexmedetomidine (1 $\mu \mathrm{g} / \mathrm{kg}$ ) was satisfactory enough to reduce Heart Rate (HR) and blood pressure during extubation without any incidence of bradycardia, hypotension and excessive postoperative sedation. When Turan et al. [15] and Guler et al. [28] used dexmedetomidine $0.5 \mu \mathrm{g} / \mathrm{kg}$ over $60 \mathrm{~s} 5 \mathrm{~min}$ before the end of the surgery to attenuate the airway reflexes and the hemodynamic during extubation, and they found Mean Arterial Pressure (MAP) and Heart Rate (HR) were significantly higher in the placebo group (control group) $(\mathrm{P}<0.05)$ than the dexmedetomidine group. These results were in agreement with the outcome of our study.

In our study, the control group, HR, DBP, SBP, and MAP were significantly increased at the peri-extubation period and after that $(\mathrm{p}<0.003)$. Despite decreased hemodynamic parameters after extubation, none of the patients in the $\mathrm{D}$ and DL groups required any clinical intervention.

Changes in HR, SBP, DBP, and MAP like maximum increase, the magnitude of improvement, number of patients having values $\geq 30 \%$ above baseline and duration of this increased episode were more in control group when compared to D and DL group. Tachycardia response was observed in $82 \%$ of the control 
group compared to $36 \%$ of the dexmedetomidine group and $40 \%$ of dexmedetomidine plus lidocaine group ( $\mathrm{p}=0.001$ ). The hypertensive response was observed in $80 \%$ of patients in the control group compared to $18 \%$ in the dexmedetomidine group and $24 \%$ in dexmedetomidine plus lidocaine group which was statistically significant $(p=0.001)$. Hypertensive response $(p=0.032)$ and duration of tachycardia $(\mathrm{p}=0.001)$ were higher in the control group compared to other two groups.

Lignocaine also has been used to decrease these reflexes during extubation [7] [8]. It attenuates the hemodynamic response to tracheal extubation by its direct myocardial depressant effect, central stimulant effect, peripheral vasodilatory effect, and finally, it suppresses the cough reflex, an impact on synaptic transmission [12].

As the pharmacological mechanism controlling the hemodynamic changes during extubation is different between dexmedetomidine and lidocaine, the concomitant use of these drugs may enhance the protective effect of each drug alone for this purpose. Therefore, our study was designed to compare the efficacy of low dose of dexmedetomidine plus lidocaine with dexmedetomidine alone in suppressing the hemodynamic changes and catecholamine responses during extubation in abdominal surgery.

We have used extubation quality scale, which is assessed by a 5 point where score 1 implies smooth extubation and rating of 5 was reduced. The average extubation quality in groups N, D and DL were 2.67, 1.93 and 1.51 respectively. Dexmedetomidine plus lidocaine group had smoother extubation quality than Dexmedetomidine alone group.

During the latter part of the observation, the sedation score was comparable, and none of the patients in any group needed for any clinical intervention apart from routine post-operative monitoring. Aldrete's recovery score [10] [29] was used to detect the recovery and readiness for discharge from the post-anesthesia care unit (PACU) which was similar in the three groups studied.

Park and Jee had compared the effect of $2 \%$ lignocaine in a dose of $1 \mathrm{mg} / \mathrm{kg}$ given endotracheal and intravenously $5 \mathrm{~min}$ and $3 \mathrm{~min}$ before extubation, respectively. In the results, when lignocaine given endotracheally was better than the IV lignocaine in attenuating airway circulatory reflexes during extubation [10].

Dexmedetomidine had the overall reasonable control of hemodynamics, smoother extubation quality, uneventful recovery, and post-anesthesia discharge. In our study, both dexmedetomidine $(1 \mu \mathrm{g} / \mathrm{kg})$ and low combined dose of dexmedetomidine $(5 \mu \mathrm{g} / \mathrm{kg})$ plus lidocaine $(1 \mathrm{mg} / \mathrm{kg})$ respectively group were useful in mitigating this emergence stress response without prolonging recovery, but low combined dose of Dexmedetomidine $(0.5 \mu \mathrm{g} / \mathrm{kg}$ plus Lidocaine $1 \mathrm{mg} / \mathrm{kg})$ IV was helpful as much as Dexmedetomidine $1 \mu \mathrm{g} / \mathrm{kg}$ IV in attenuating hemodynamic stress responses during emergence. In DL group was low sedation score and high extubation quality in comparison to D group with no clinically significant differences in sedation and extubation quality. 


\section{Conclusions}

Single dose of Dexmedetomidine $1 \mu \mathrm{g} / \mathrm{kg}$ intravenous or low combination dose of dexmedetomidine plus lidocaine $0.5 \mu \mathrm{g} / \mathrm{kg}, 1 \mathrm{mg} / \mathrm{kg}$ respectively intravenous bolus infusion administered 10 minutes before extubation was effective in attenuating hemodynamic stress response during extubation. Dexmedetomidine was efficacious compared to dexmedetomidine plus lidocaine in mitigating emergency response. Extubation quality was superior to dexmedetomidine plus lidocaine compared dexmedetomidine or control group. As regarding sedation score and recovery profile, in the DL group were low sedation score and high extubation quality in compared to D group with no clinically significant differences in sedation and extubation quality. D and DL groups had smoother and best extubation quality. Decreasing of emergence stress response should be routine than an optional entity in day to day clinical practice.

\section{Conflicts of Interest}

The authors declare no conflicts of interest regarding the publication of this paper.

\section{References}

[1] Minogue, S.C., Ralph, J. and Lampa, M.J. (2004) Laryngotrachealtopicalization with Lidocaine before Intubation Decreases the Incidence of Coughing on Emergence from General Anesthesia. Anesthesia \& Analgesia, 99, 1253-1257.

https://doi.org/10.1213/01.ANE.0000132779.27085.52

[2] Cook, T.M., Scott, S. and Mihai, R. (2010) Litigation Related to Airway and Respiratory Complications of Anesthesia: An Analysis of Claims against the NHS in England 1995-2007. Anaesthesia, 65, 556-563.

https://doi.org/10.1111/j.1365-2044.2010.06331.x

[3] Peskett, M.J. (1999) Clinical Indicators and Other Complications in Their Recovery Room or Postanaesthetic Care Unit. Anaesthesia, 54, 1143-1149.

https://doi.org/10.1046/j.1365-2044.1999.01077.x

[4] Rose, D.K., Cohen, M.M., Wigglesworth, D.F. and De Boer, D.P. (1994) Critical Respiratory Events in the Postanesthesia Care Unit. Patient, Surgical, and Anesthetic Factors. Anesthesiology, 81, 410-418. https://doi.org/10.1097/00000542-199408000-00020

[5] Mhyre, J.M., Riesner, M.N., Polley, L.S. and Naughton, N.N. (2007) A Series of Anesthesia-Related Maternal Deaths in Michigan, 1985-2003. Anesthesiology, 106, 1096-1104. https://doi.org/10.1097/01.anes.0000267592.34626.6b

[6] Auroy, Y., Benhamou, D., Péquignot, F., Bovet, M., Jougla, E. and Lienhart, A. (2009) Mortality Related to Anesthesia in France: Analysis of Deaths Related to Airway Complications. Anaesthesia, 64, 366-370. https://doi.org/10.1111/j.1365-2044.2008.05792.x

[7] Lewis, G. (2007) The Confidential Enquiry into Maternal and Child Health (CEMACH). Saving Mothers' Lives: Reviewing Maternal Deaths to Make Motherhood Safer-2003-2005. The Seventh Report on Confidential Enquiries into Maternal Deaths in the United Kingdom. CEMACH, London, 7.

[8] Asai, T., Koga, K. and Vaughan, R.S. (1998) Respiratory Complications Associated 
with Tracheal Intubation and Extubation. British Journal of Anaesthesia, 80, 767-775. https://doi.org/10.1093/bja/80.6.767

[9] Batra, Y.K., Singh, H. and Singh, S.P. (1986) Blood Pressure and Pulse Rate Changes during Tracheal Extubation, the Influence of Topical or Intravenous Lidocaine. Indian Journal of Anaesthesia, 34, 31-34.

[10] Jee, D. and Park, S.Y. (2003) Lidocaine Sprayed Down the Endotracheal Tube Attenuates the Airway-Circulatory Reflexes by Local Anesthesia during Emergence and Extubation. Anesthesia \& Analgesia., 96, 293-297.

https://doi.org/10.1097/00000539-200301000-00058

[11] Sharma, V.B., Prabhakar, H., Rath, G.P. and Bithal, P.K. (2014) Comparison of Dexmedetomidine and Lignocaine on the Attenuation of Airway and Pressor Responses during Tracheal Extubation. Journal of Neuroanaesthesiology and Critical Care, 1, 50-55.

[12] Savitha, K.S., D'Souza, J.S. and Kothari, A.N. (2014) Attenuation of Hemodynamic Response to Extubation with I.V. Lignocaine: A Randomized Clinical Trial. Journal of Evolution of Medical and Dental Sciences, 3, 838-846.

[13] Jain, D., Khan, R. and Maroof, M. (2009) Effect of Dexmedetomidine on Stress Response to Extubation. The Internet Journal of Anesthesiology, 21.

[14] Nishina, k., Mikawa, K., Maekawa, N. and Obara, H. (1995) Fentanyl Attenuates Cardiovascular Responses to Tracheal Extubation. Acta Anaesthesiologica Scandinavica, 39, 85-89. https://doi.org/10.1111/j.1399-6576.1995.tb05597.x

[15] Turan, G., Ozgultekin, A., Turan, C., Dincer, E. and Yuksel, G. (2008) Advantageous Effects of Dexmedetomidine on Hemodynamic and Recovery Responses during Extubation for Intracranial Surgery. European Journal of Anaesthesiology, 25, 816-820. https://doi.org/10.1017/S0265021508004201

[16] LeBlanc, J.M., Joseph, F., Maria, C., Gerlach, A. and Cook, C. (2012) Bispectral Index Values, Sedation-Agitation Scores, and Plasma Lorazepam Concentrations in Critically Ill Surgical Patients. American Journal of Critical Care, 21, 99-104.

[17] Ramsay, M.A., Huddleston, P., Hamman, B., Tai, S. and Matter, G. (2004) The Patient State Index Correlates Well with the Ramsay Sedation Score in ICU Patients. Anesthesiology, 101, A338.

[18] Alkaya, M.A., Saraçoglu, K.T., Pehlivan, G., Eti, Z. and Goguş, F.Y. (2014) Effects of Esmolol on the Prevention of Hemodynamic Responses to Tracheal Extubation after Craniotomy Operations. Turkish Journal of the Anaesthesiology and Reanimation, 42, 86-90.

[19] Cook, T.M., Woodall, N. and Frerk, C. (2011) 4th National Audit Project: Major Complications of Airway Management in the UK. Royal College of Anaesthetists, London, 62-70.

[20] Peterson, G.N., Domino, K.B., Caplan, R.A., Posner, K.L., Lee, L.A. and Cheney, F.W. (2005) Management of the Difficult Airway: A Closed Claims Analysis. Anesthesiology, 103, 33-39. https://doi.org/10.1097/00000542-200507000-00009

[21] Guler, G., Akin, A., Tosun, Z., Eskitascoglu, E., Mizrak, A. and Boyaci, A. (2005) Single-Dose Dexmedetomidine Attenuates Airway and Circulatory Reflexes during Extubation. Acta Anaesthesiologica Scandinavica, 49, 1088-1091. https://doi.org/10.1111/j.1399-6576.2005.00780.x

[22] Aksu, R., Akin, A., Biçer, C., Esmaoğlu, A., Tosun, Z. and Boyaci, A. (2009) Comparison of the Effects of Dexmedetomidine versus Fentanyl on Airway Reflexes and Hemodynamic Responses to Tracheal Extubation during Rhinoplasty: A Double-Blind, Randomized, Controlled Study. Current Therapeutic Research, 70, 209-220. 
https://doi.org/10.1016/j.curtheres.2009.06.003

[23] Tanskanen, P.E., Kyttä, J.V., Randell, T.T. and Aantaa, R.E. (2006) Dexmedetomidine as an Anesthetic Adjuvant in Patients Undergoing Intracranial Tumor Surgery: A Double-Blind, Randomized and Placebo-Controlled Study. British Journal of Anaesthesia, 97, 658-665. https://doi.org/10.1093/bja/ael220

[24] Sağıroğlu, A., Celik, M., Orhon, Z., Yüzer, S. and Sen, B. (2010) Different Doses of Dexmedetomidine on Controlling Haemodynamic Responses to Tracheal Intubation. The Internet Journal of Anesthesiology, 27, No. 2.

[25] Wang, B.S., Yu, J.B., Wang, F., Zhang, L., Zhang, Y. and Li, S.Q. (2012) Effect of Dexmedetomidine on Stress Responses during Extubation in Patients Undergoing Uvulopalatopharyngoplasty. Chinese Journal of Otorhinolaryngology Head and Neck Surgery, 47, 498-501.

[26] Bindu, B., Pasupuleti, S., Gowd, U.P., Gorre, V., Murthy, R.R. and Laxmi, M.B. (2013) A Double-Blind, Randomized, Controlled Trial to Study the Effect of Dexmedetomidine on Hemodynamic and Recovery Responses during Tracheal Extubation. Journal of Anaesthesiology Clinical Pharmacology, 29, 162-167. https://doi.org/10.4103/0970-9185.111665

[27] Sebastian, B., Talikoti, A.T. and Krishnamurthy, D. (2017) Attenuation of Hemodynamic Responses to Laryngoscopy and Endotracheal Intubation with Intravenous Dexmedetomidine: A Comparison between Two Doses. Indian Journal of Anaes thesia, 61, 48-54.

[28] Guler, G., Akin, A., Tosun, Z., Eskitascoglu, E., Mizrak, A. and Boyaci, A. (2005) Single-Dose Dexmedetomidine Attenuates Airway and Circulatory Reflexes during Extubation. Acta Anaesthesiologica Scandinavica, 49, 1088-1091.

https://doi.org/10.1111/j.1399-6576.2005.00780.x

[29] Phillips, N.M., Street, M., Kent, B., Haesler, E. and Cadeddu, M. (2013) Post-Anesthetic Discharge Scoring Criteria: Key Findings from a Systematic Review. International Journal of Evidence-Based Healthcare, 11, 275-284.

http://dx.doi.org/10.1111/1744-1609.12044 